\title{
SODRÉ, M. (2013). UM NOVO SISTEMA DE INTELIGIBILIDADE. REVISTA DE EPISTEMOLOGIAS dA COMUNiCAÇÃo, 1(1), 66-73.
}

\author{
Francisco Manuel Calado Gomes Abrunhosa
}

Muniz Sodré é jornalista, sociólogo e tradutor brasileiro. Possui a licenciatura em Direito pela Universidade Federal da Baía (1964), o mestrado em Sociologia da Informação e Comunicação pela Université de Paris IV (Paris-Sorbonne) (1967) e é doutorado em Ciência da Literatura pela Universidade Federal do Rio de Janeiro (1978). É professor-titular da Universidade Federal do Rio de Janeiro (UFRJ), onde dá aulas há mais de três décadas como livre-docente. Durante cinco anos, até 2012, esteve na direção da Fundação Biblioteca Nacional do Brasil. Anteriormente dirigiu a TV Educativa. Possui cerca de 30 livros publicados nas áreas de Comunicação e Cultura e também escreve ficção'.

Em tempos de globalização e do primado tecnológico Muniz Sodré procura contribuir para o debate sobre o lugar do humano no mundo, chamando a terreiro várias áreas científicas que, concatenadas, permitam, na perspetiva do autor, conceber a estrutura do que chama "novo sistema de inteligibilidade".

Afirma o autor que durante o século XX, o campo científico da comunicação ficou marcado pelo paradigma sociológico americano. Porém, com a paulatina passagem da economia de produção industrial para a economia de serviços ou financeira, o paradigma de análise passou a centrar-se nos indivíduos, dirigindo-se a grupos sociais. Afirma Sodré que nesse momento se assistiu à consolidação da "presença avassaladora do 'objeto técnico'" (Sodré, 2013, p. 66). O autor apoia-se noutras referências da escola de Frankfurt (entre os quais Adorno, Habermas e Marcuse) e também da corrente do pós-modernismo (entre os quais Lyotard e Lipovetsky). No conjunto, todos esses autores foram, a seu modo, críticos à progressiva conversão da cultura em eixo de produtividade, fenómeno que também ficou conhecido pela terminologia "Indústria Cultural”, ainda na primeira metade do século passado, isto é, num tempo em que tanto Adorno como Marcuse introduziram no discurso a hipótese do "apocalipse da paideia" (p. 66).

Hoje, afirma Sodré, o que se discute é a ideia segundo a qual o poder tecnológico representa a "vontade de poder" (p. 66), não como uma prática de dominação, mas como "força que possibilita a expansão da vida" (p. 66). Daí a insistência do autor na palavra "tecnologia", - a que que melhor designa "a racionalidade que emerge do próprio universo instrumental das máquinas" (p. 67). Sendo a tecnologia o fulcro e a ferramenta do discurso, poderá “levar à reformulação da ideia humanista do antropocentrismo

\footnotetext{
' Informação Retirada de http://www.revistaovies.com/entrevistas/2012/03/muniz-sodre-o-capital-nao-gosta-de-gente-o-capital-gosta-de-capital/.

2 Processo de educação da Grécia antiga de Platão, através do qual se procura a Verdade, a sustentação do cidadão completo.
} 
biológico" (p. 67), quer dizer, para Sodré há na tecnologia um poder explícito dos bens materiais sobre a vida humana e, por isso, percebe-se "o transe existencial das transformações e passagens, tal como o entende a tradição de pensamento" (p. 67).

Segundo Sodré, com o esboroar dos referenciais identitários republicanos e humanistas, perderam sentido as bandeiras que alimentavam a coesão social simbólica. Estas são abaladas pela dependência face às máquinas, enquanto o edifício político se constitui na tecnocracia e a universalidade mais sólida passa a ser a dos mercados numa sociedade cada vez mais mediatizada. É exatamente por isso que Sodré considera ser do espaço da comunicação de onde poderá emergir o conhecimento que reabilite a razão da existência humana (p. 67). Isto é, na perspetiva do autor, "o pensamento social requer um novo sistema de inteligibilidade para a diversidade processual da comunicação enquanto ciência específica do modo de produção ativo de conhecimento" (p. 67): a emergência desse pensamento social deverá passar pela releitura do logos que preside à vinculação social dos sujeitos, seja qual for a terminologia (ou o pensamento filosófico) a utilizar: "(Destruktion em Heidegger, desconstrução em Derrida, arqueologia em Foucault, redescrição em Rorty, etc.)" (p. 67). Uma releitura que consiga "escutar as vozes constitutivas do novo âmbito tecnológico habitado pelo homem" (p. 67), não apenas à luz da filosofia ou das ciências sociais, mas num diálogo conjunto de hipóteses de pensamento que possibilite o surgimento de um novo modelo de inteligibilidade. Trata-se de reler, reinterpretar, no sentido "nietzscheano de reavaliação de valores" (p. 67), de modo a encontrar um "novo horizonte educativo ou autoeducativo capaz de reequilibrar a consciência do sujeito em face da violência semiótica da globalização" (p. 67). Para ilustrar essa abertura, esse reinterpretar, que liberte o pensamento científico de pressupostos cristalizados, Muniz Sodré recorre a Jacques Lacan, psicanalítico, e a Rorty, filósofo, ambos em rutura com o status quo.

Assim, para Sodré,

o campo científico da comunicação (...) pode vir a definir-se (...) como um dispositivo de releitura das questões tradicionais da sociedade (...), sem as (...) barreiras entre as antigas disciplinas, mas também entre a redescrição científica e a criação de natureza artística, com todos os seus recursos imaginativos, dos quais não se excluem as metáforas (p. 68)

À ordem societária que emerge da imposição dos meios de comunicação, a qual reifica e coisifica os indivíduos, Muniz Sodré dá o nome de bios virtual. O poder deste bios virtual reside nas relações codificadas que estão acima da consciência individual do sujeito: é um modelo totalmente ligado aos produtos e aos mercados: é o espetáculo, diz Sodré, usando a terminologia de Guy Debord (1967, p. 15).

A análise redescritiva do espetáculo ou bios virtual que, como declara Sodré, "pode ser entendida como um convite a se ler novamente" (p. 69) - por palavras nossas: a oferecer-se a uma releitura desconstrutiva, por um processo defendido pelos pósmodernistas da qual pode resultar o surgimento de um novo sistema de inteligibilidade alternativo ao pensamento hegemónico vigente. Para tanto, essa operação redescritiva, 
considera Sodré, não deve coibir-se de se valer dos recursos gerados pelo próprio bios tecnológico, de forma crítica e politicamente empenhada, de modo a acrescentar valor aos acontecimentos, isto é, mediante criatividade inventiva e sem preconceitos aristotélicos, epistemológicos ou ideológicos e utilizando os meios audiovisuais, fílmicos e/ ou informáticos. Nesse sentido Sodré considera, seguindo a análise de Deleuze, a obra do cineasta Jean Luc Godard um bom exemplo desse processo interventivo que emerge do interior do próprio sistema. Outro bom exemplo prende-se com a generalização do uso da internet no domínio do texto redescritivo: à anterior estabilidade pouco interativa entre pares de uma comunidade académica fechada, sucedeu-se uma profusão de publicações eletrónicas, seguida de não menos comentários críticos, num escrutínio público inigualável, em que a sobreposição de novos textos torna obsoletos os textos teóricos que os precedem, obrigando a uma atenção redobrada dos académicos na atualização constante dos seus trabalhos. A internet incrementa, assim, o poder redescritivo, força o diálogo entre académicos num sentido público de partilha coletiva. Dá-se uma apropriação criativa e anónima dos discursos que, segundo Sodré, rompe com a tradicional imagem "espelhada entre o enunciado e a suposta verdade factual do mundo" (p. 70). Porém, a redescrição não deve ser encarada senão como uma interpretação da realidade, com tudo o que esta afirmação encerra de pleonástico, acrescentamos nós, uma vez que, como recorda Sodré, "a realidade enquanto tal já é ela própria uma interpretação (exatamente de acordo com a indicação nietzscheana de que 'não há fatos (sic), só interpretações')" (p. 70) apenas à espera de uma próxima reinterpretação inventiva que ponha a anterior em causa.

Tudo isso depende de um novo intérprete-redescritor, para a emergência do qual, segundo Muniz Sodré, muito contribuiu Michel Foucault. Aliás, como afirmam as palavras do próprio Foucault: "achei que (...) era o essencial: libertar a história do pensamento da sua sujeição transcendental (...); abri-la a uma temporalidade que não prometeria o retorno de nenhuma aurora" (Foucault, 1969, p. 227), num incentivo à superação das barreiras disciplinares e dos aspetos metodológicos e doutrinários.

Todavia, esse intérprete-redescritor necessita de um mediador, função que Sodré reafirma caber à comunicação, um espaço de interseção entre as ciências sociais e a filosofia, prenunciando que a ciência da comunicação funcionará como "uma plataforma interpretativa (...) de relações sociais de comunicação" (p. 70), atuando no seio do bios virtual e visando transcendê-lo, pragmaticamente, de forma a ser "capaz de ultrapassar o paradigma cognitivo hegemónico" (p. 70).

Mas esse intérprete-redescritor terá de atuar num espaço público que se transformou num lugar de não inscrição, reflexo tecnicamente ampliado do existente na direção da sociedade que o reproduz. Ao deslumbre permanente pela técnica, visto como uma inevitabilidade - que consigo arrasta tantas outras inevitabilidades -, Sodré classifica como "a visão que se tem do puro espetáculo (...) capaz de emocionar sem produzir a lucidez sensível ou o sentimento" (p. 71), numa nova referência a Debord (1967), da obra de quem, porém, achamos dever acrescentar: 
O espetáculo não pode ser compreendido como abuso do mundo da visão ou produto de técnicas de difusão massiva de imagens. Ele é a expressão de uma weltanschaunung [visão do mundo] materialmente traduzida. (...) $\mathrm{O}$ espetáculo é ao mesmo tempo parte da sociedade, a própria sociedade e o seu instrumento de unificação. (Debord, p.14)

Daí a impossibilidade de isolar e interpelar, a partir de fora, o agente que está por trás desse espetáculo; e daí a necessidade de intervenção, sim, mas no lado de dentro: no espaço público, um espaço comum de comunicação do cidadão com a sociedade, elemento agregador da polis, sobre o qual também reflete o filósofo José Gil (2004) e que aqui referimos: "esse é um espaço aberto de expressão e trocas, essencial para que a liberdade e a criação circulem no campo social (...), [é um] fora que faz toda riqueza da expressão pública" (Gil, 2004, p. 25). Porém, esse espaço foi sendo paulatinamente dominado pelas corporações mediáticas, num processo a que o autor do artigo denomina "culturalização", determinando o desaparecimento da sua pluralidade democrática em favor da lógica mercantil, "convertendo a vida pública em vida em público" (Sodré, p. 71). É que, apesar da livre circulação e discussão de ideias terem sido bastante alargadas com a evolução exponencial das tecnologias da informação, esse alargamento aconteceu, diz Sodré, apenas nas suas "dimensões materiais e funcionais, sem real correspondência histórica com o que antes significavam política e cultura" (p. 71).

Aliás, ao consultarmos Hall (1997) este é mais contundente quando diz que "hoje, os media sustenta[m] os circuitos globais de trocas económicas dos quais depende todo o movimento mundial de informação, conhecimento, capital, investimento, produção de bens, comércio de matérias-primas e marketing de produtos e ideias" (Hall, 1997, p. 2). Enfim, é toda uma indústria que se move no sentido de garantir o fluir de informação que prenda a atenção das massas, num frenesim de entretenimento sem preocupações intelectuais. Por isso, urge conceber uma "outra plataforma interpretativa do fenómeno comunicacional” (p. 71), já que é crucial proceder ao resgate político "da condição humana, no âmbito das novas configurações do capital e da tecnologia" (p. 11).

Contudo, essa nova plataforma interpretativa só é possível de conceber, insiste Sodré, no decurso de uma redescrição que ultrapasse "a dicotomia entre ciência social (sic) e humanidades" (p. 71), de que resultará um processo de redescrição ontológica multifacetada do modo de existir do Homem no bios virtual, "por mais que este [bios virtual] tente legitimar-se pela ideologia prazerosa do consumo e da eficácia tecnológica ininterrupta" (p. 1). A redescrição do capitalismo liberal deve debruçar-se sobre a "problematização heideggeriana da desorientação atual do homem" (p. 71), que vai mostrando as razões da fixação do homem nos objetos e na sua multiplicação, "expondo a volúpia fetichista da economia" (p. 71).

O texto que Sodré nos apresenta é, assim, mais do que uma reflexão sobre mudanças sociais. É um texto que discute um conceito próprio - o de sistema de inteligibilidade-apresentando argumentos em favor de estratégias teóricas e sobretudo analíticas que permitem uma leitura dos processos de mudança social, assim como e, sobretudo, 
a delimitação de estratégias de subversão face a hegemonias dominantes ligadas ao avanço da tecnologia, nomeadamente ao que o autor classifica como sendo a "violência semiótica da globalização".

\section{REFERÊNCIAS BIBLIOGRÁFICAS}

Debord, G. (1967). A sociedade do espetáculo. Brasil: ebooksBrasil.com [eBook]. Retirado de http://www. ebooksbrasil.org/adobeebook/socespetaculo.pdf

Foucault, M. (1969). A arqueologia do saber. Ed. Forense Universitária: Rio de Janeiro.

Gil, J. (2004). Portugal, hoje - o medo de existir. Lisboa Ed. Relógio D’Água Editores.

Hall, S. (1997). A Centralidade da Cultura: Notas sobre as revoluções culturais do nosso tempo. Retirado de https://www.google.pt/webhp? sourceid=chrome-instant\&ion=1\&espv=2\&ie=UTF-8\#q=a\%20 centralidade\%20da\%20cultura\%2ostuart\%2ohall\%2oresumo.

Sodré, M. (2013). Um novo sistema de inteligibilidade. Revista de Epistemologias da Comunicação, 1(1), 66-73.

\section{NOTA BIOGRÁFICA}

Francisco Calado Abrunhosa é licenciado em Estudos Culturais pelo Instituto de Letras e Ciências Humanas da Universidade do Minho (2014/15) e mestrando em Comunicação Arte e Cultura - Instituto de Ciências Sociais da Universidade do Minho (2015/16). Desempenha funções na câmara municipal de Braga.

E-mail: franciscoabrunhosa_@hotmail.com

* Submetido: 10-10-2015

* Aceite: 10-11-2015 